\title{
İnşaatta Proje Yönetimi; Projenin Başarısına Etkisi
}

\author{
Rüveyda KÖMÜRLÜ ${ }^{1}$, Leyla TOLTAR ${ }^{2 *}$
}

Öz

Günümüzde yapılan ve yapılacak olan projelerin daha kapsamlı ve kompleks bir yapıya sahip olmalarından dolayı proje yönetiminin önemi her geçen gün artmakta ve proje yönetiminin firmalar tarafından yaygın olarak kullanılmasını zorunlu hale getirmektedir. Proje yönetiminin kapsamı dâhilinde olan planlama, proje metodolojisi ve proje tekniği inşaat projelerinde projenin başarısına etki eden etkenlerdir. Projelerin ulaşılması düşünülen hedeflere, istenilen tarihlerde ulaşabilmesi proje için belirlenen planlamanın uygulanması ile gerçekleşir. Tüm detayların, hangi aktivitenin ne zaman ve hangi sırayla gerçekleşeceğinin planlanması projenin en verimli, en kaliteli ve en az maliyetle başarıya ulaşmasını sağlayacaktır. Bunun yanı sıra projenin başarıya ulaşması projeye özgü olarak belirlenen proje tekniği ve proje metodolojisine bağlıdır. Çok sayıda kullanılan proje metodolojisi ve proje tekniği bulunmaktadır. Uygulanacak olan projenin hangi metodoloji ve teknikle yönetileceği projenin özelliklerine göre belirlenmektedir.

Günümüzde rekabet ortamının artması ve projelerin komplike hale gelmesiyle inşaat firmalarının daha az insan gücü, daha çok koordine ile faaliyetleri organize etme çabalarını ortaya çıkarmıştır. Her proje kendine has özelliklere sahip olduğu için, yine kendine has proje yönetimi ile yönetilmelidir. Buna göre yürütülecek olan inşaat projesi uygun proje metodolojisi ve proje tekniklerinden oluşan proje yönetimi ile yönetilmelidir. Uygun proje tekniği ve proje metodolojisinden oluşan proje yönetimi inşaat projesinin başarıya ulaşmasındaki en temel ve önemli rolü oynar. Bu makalede proje ve proje yönetim kavramları, proje yönetim metodolojileri, proje bilgi alanları, proje yönetim süreçleri ve proje teknikleri aktarılarak inşaatta proje yönetiminin projenin başarısına etkilerinin anlaşılması hedeflenmiştir. Sonuç kısmında proje yönetimini oluşturan olan proje metodolojileri, proje yönetim süreçleri, proje yönetimi bilgi alanları ve proje tekniklerinin inşaat projelerinin başarılarında nasıl etkileri olduğunu, proje yönetimi içerisinde nasıl uygulanması gerektiği aktarılmıştır.

Anahtar Kelimeler: Proje Yönetimi, Planlama, Proje Teknikleri, Proje Metodolojileri

\section{Project Management in Construction and Its Effect on Project's Success}

\begin{abstract}
Construction projects are growing bigger and becoming more complex in time, which emphasizes the importance of project management. Since project management increases effectiveness, firms aiming to be competitive prefer project management practices. Project management includes planning, process management, scope and quality management, which effect the success of the projects directly. Schedules and methods need to be applied and tracked in order for the projects to reach the desired targets. Planning the sequence of the activities is essential to complete a project on the desired date. Besides, success of a project depends on the project management methodology, which should be chosen regarding the characteristics of the project.
\end{abstract}

\footnotetext{
${ }^{1}$ Kocaeli Üniversitesi, Mimarlık ve Tasarım Fakültesi, Mimarlık Bölümü, İzmit, Kocaeli

${ }^{2}$ Kocaeli Üniversitesi, Fen Bilimleri Enstitüsü., Mimarlık Ana Bilim Dalı Yüksek Lisans Programı

* Illgili yazar / Corresponding Author: leylatoltar@hotmail.com

Gönderim Tarihi: 28.11.2018

Kabul Tarihi: 26.12.2018
} 
Competence in the construction industry directs the companies to savings in workforce via increasing efficiency. Coordination of activities has special importance at this point. Since, every project has its own characteristics, project management methodology should be chosen according to these. Applying the proper project management methodology has the key role for the success of a project. This paper aims to evaluate the effect of project management on a project's success. For this, project management terms, project management methodologies, project knowledge areas, project management processes, and project management techniques are reviewed. It has been found that, choosing the project management methodology regarding the size and scope of the project, building the appropriate organization chart, forming a project management team with appropriate know-how, capabilities and experience, and applying the processes of the chosen project management methodology have the key role for the success of a project.

Keywords: Project management, Planning, Project methodologies, Project knowledge areas, Project management techniques

\section{Giriş}

Ülke ekonomilerinin büyümesindeki en büyük pay; tarım, endüstri ve inşaat gibi sektörlere aittir. Bu sektörler içerisinde de inşaat sektörü en büyük payı almaktadır. Gayrisafi Yurtiçi Hasıla (GSYH) içerisinde inşaat sektörünün payının \%30 seviyesinde olduğu görülmektedir(KPMG, 2018, s.4).Ülke ekonomisinde önemli bir paya sahip olan inşaat sektöründe üretilen projelerin istenen süre, kalite ve belirli bütçe içinde kalarak tamamlanması koordineli bir çalışma ile mümkündür. Bu koordineli çalışma proje yönetimi kavramı içerisinde oluşturulmaktadır. Proje yönetiminin inşaat projesinde başarılı bir şekilde uygulanması proje yönetimi teknikleri ve proje yönetimi metodolojilerinin koordinasyonu ile gerçekleşmektedir.

İnşaat sektörü içerisinde üretilen projelerin gecikmeden, mevcut kaynakların kullanılarak istenilen hedefe ulaştırılması ve hata riskinin en aza indirgendiği ortamın oluşturulması proje gerçekleşirken oluşan sorunların çözüme ulaştırılması ile mümkündür.

Proje yönetimi projelerin nasıl ve ne şekilde yönetilmesiyle ilgili belirli kuralları olan bir disiplindir. Proje yönetimi planlanmış bir yaklaşımın yokluğunda projelerin başarılı bir şekilde sonuçlandırılamadığının görülmesi üzerine son birkaç on yıl içinde geliştirilmiştir. Proje yönetiminin amacı projelerin başarılı olarak tamamlanması ve nihai noktaya ulaşılmasıdır (Newton, 2006, s. 17).

$\mathrm{Bu}$ makalede, inşaatta proje yönetiminin inşaatın istenilen hedefe ulaşmasında ne kadar etkili ve önemli olduğunun ortaya koyulması amaçlanmıştır. Bu doğrultuda, proje yönetimini oluşturan süreçler ve bilgi alanları ile ilgili olarak literatür taraması yapılmış, proje yönetiminin ortaya çıkışından itibaren tarihçesi ele alınmıştır. Takiben, proje yönetim metodolojileri ve teknikleri incelenmiş, proje yönetiminin hangi süreçlerden ve bilgi alanlarından oluştuğu, teknik ve metodolojilerin nasıl uygulanması gerektiği aktarılarak tüm bunların projenin başarısına olan etkileri vurgulanmıştır. 


\section{Proje ve Proje Yönetimi Kavramları ve Tarihsel Gelişimi}

\subsection{Proje}

Proje, bir sorunu ortadan kaldırmak için ya da bir intiyacın karşılanması için bir amaca yönelik olan, başlangıç ve bitiş zamanları belli olan, tek defaya mahsus yapılan bir organizasyon çerçevesinde gerçekleşen üretimdir.

Proje, insanların kafalarında oluşturdukları bir düşünceyi uygulama evresine geçirmesi ve hedefine ulaşmasıyla sona eren bir süreçtir (Ayaydın, 2000, s.5).

\subsection{Proje yönetimi}

Proje yönetimi projenin belirlenen zaman, kapsam ve maliyet hedeflerine ulaşması için gerekli olan tüm adımların planlanması, uygulanması ve kontrolüdür.

Proje yönetimi; projenin hedefine ulaşması için intiyaç olan farklı organizasyonların projenin hacmine, süresine, maliyetine ve büyüklüğüne uygun bir şekilde bir araya getirilmesi ve bunların yönetilmesidir (Kocakulak,1997, s.4).

Benzersiz ve bir defaya mahsus olmak üzere uygulanan projelerin süre, maliyet, kapsam ve kalite hedeflerine varması için belirlenen kaynakların, belirli teknik ve metodolojiler ile gerçekleştirilmesi olarak tanımlanabilir proje yönetimi.

\subsection{Proje yönetimi tarihsel gelişimi}

Proje yönetimi tarihi, tarih öncesi dönemlerde oluşturulan Mısır piramitleri ve Çin seddi gibi eserlerin yapım dönemine dayanmaktadır. Ancak günümüzde var olan proje yönetimi 20.yy zamanlarına dayanmaktadır. Tarih öncesi dönemlerde yapılmış olan projeler, zamanın şartlarına ve kurallarına özgü yönetim teknikleri ile uygulanıyordu.

Örneğin insan yerleşimleri, Çin Seddi, Mısır piramitleri gibi tarih öncesinde oluşan pek çok proje uygarlık tarihinde oluşmuştur. Bunun yanı sıra Roma, Bizans, Hun ve Osmanlı gibi büyük devlet ordularının yapmış oldukları seferlerde proje olarak nitelendirilebilir. Ve bu projelerin yönetimi, proje yönetim kavramlarının kullanımı ile gelişmiştir(Günaydın, 2001, Çalışkan,2009, s.5).

İlk olarak proje yönetim danışmanı Frederick Taylor 20. yy başlarında proje yönetimine bilimsel yaklaşımlar yapmıştır. Taylor 1917 yılında Gantt şemasını geliştirdi. Ayrıca proje yönetimi tekniklerinden olan PERT ve CPM'yi geliştirdi.

İkinci Dünya savaşı sonrasında sanayinin de gelişmesi ile beraber azalan işgücü intiyacı şirketlerin yeni proje yönetim tekniklerinin oluşmasını sağlamıştır. Bu nedenle Gantt diyagramının daha gelişmiş şekli olan CPM ve PERT yöntemleri ilk kez 1958 yılında Amerikan ordusunda deniz füzelerinin yapımı projesinde kullanılmaya başlanmıştır.

Özetle, proje yönetiminin ortaya çıktığı yıllar olan 1950'lerde;ilk defa bir birey proje yöneticisi olarak tanınmış ve bu bireye projenin hedeflerini gerçekleştirme sorumluluğu verilmiştir. Yine ilk defa 1950'li yıllarda proje süre yönetimi ile ilişkili olarak proje 
yönetimi yaklaşımının temel araçları olan ağ diyagram teknikleri geliştirilmiştir(Ata, 2009, s.11).

1970 yıllar ve sonrasında var olan teknikler geliştirilmiş, yeni teknikler üretilmiştir. PMI ve IPMA'nın çalışmaları ile proje yönetimi bağımsız bir meslek olarak kabul görmüştür. PMI tarafından profesyonel proje yönetim standardı olan PMBOK oluşturulmuştur. 1986 yılında yayınlanan PMBOK'ta süre ve maliyet yönetimi tekniklerinin yanına proje kapsam, kalite, risk, insan kaynakları, iletişim, sözleşme/tedarik teknikleri eklenmiş ve proje yönetiminin bilgi alanları genişletilmiştir (Ata, 2009, s.12).

\section{Proje Yönetimi Metodolojileri}

Proje yönetim metodolojisi yürütülecek projelerin etkin şekilde yönetilmesi adına oluşturulmuş prosedür olarak tanımlanabilir. Dünyada ve ülkemizde kullanılan çeşitli proje yönetim metodolojileri vardır. Bunlar içerisinde en çok kullanılan Amerikan menşeili PMI(Project Management Institute-Proje Yönetim Enstitüsü) metodolojisi, IPMA(International Project Management Association-Uluslararası Proje Yönetim Derneği) ve İngiliz menşeili PRINCE2 metodolojisidir. Bu metodolojilere bağlı kalarak proje yöneticileri kendi projelerine özgü metodolojiler kullanabilir.

\subsection{PRINCE2 metodolojisi}

1989 yılında İngiliz Devlet Ticaret Ofisi(OCG) tarafından oluşturulan, daha sonrasında özel sektörün desteği ile İngiltere Devleti tarafından geliştirilen PRINCE2, bir projenin başlangıcından sonuna kadar nasıl yürütülmesi gerektiğini öğreten bir proje yönetim metodudur (Ata, 2009, s.29).

Süreç temelli bir proje yönetim metodu olan PRINCE2 kontrollü ortamlarda projeler anlamına gelir. Bu metot proje yönetimini birbirleri ile bütünleşmiş olan prensipler, temalar, süreçler ve proje ortamı unsurları ile ele alır. Prensipler, yol gösterici gerekliliklerdir. Temalar, proje süreci boyunca irdelenmesi gereken proje yönetimi açılarını tanımlar. Süreçler, proje başlangıcından bitişine kadar proje yaşam döngüsünde adım adım sürecin nasıl ilerleyeceğini tanımlar.PRINCE2'nin proje ortamına uyarlanması projenin büyüklüğüne göre değişir.

\subsection{IPMA metodolojisi}

Avrupa, Asya, Avustralya ve Amerika kıtalarında 58 üye ülkesi olan dünya çapında kabul gören, dünyanın en eski proje yönetim kuruluşudur. A,B,C,D olmak üzere 4 farklı seviye olarak sertifikasyon uygulaması vardır. Bu seviyeler bireylerin yeterlilik seviyelerine göre sınıflandırılmıştır. Yeterlilik gerekli olan bilgi birikimi, bireysel davranış ve tutumlar, yeteneklerin bir araya gelmesiyle oluşmaktadır.

IPMA'yı diğer metodolojilerden ayıran özelliği proje yöneticisinde olması gereken davranışların belirtilmiş ve açıklamalarının yapılmış olmasıdır. Bu özellik PRINCE2'de yer almamış, PMBOK içinde de sadece ana başııları ile belirtilmiştir (Ata, 2009, s.27). 


\subsection{PMI metodolojisi}

Illk kez 1969 yılında oluşturulmuştur.1969'dan günümüze kadar olan bir süreçte proje yönetiminin gelişmesi ve ilerlemesi için yapılan çalışmaların çoğunda PMI'nın yer aldığını görebiliriz (Ata,2009, s.19).

PMI metodolojisinin temel amacı proje yönetimi uygulamasını tüm dünyada, organizasyonların proje yönetimini benimseyeceği, uygulayacağı şekilde ilerletmektir. PMI üyelerinin ve tüm proje yönetici ve uygulayıcılarının küresel ve yerel en iyi uygulamaları takip etmelerini ve proje yönetim konusunda üretilen kaynakları paylaşmalarını sağlamaktadır.

PMI 1969 yılından bu zamana kadar hedeflediği amaca ulaşmak için, bireysel sertifikasyon, mesleki gelişim programları, proje yönetimi profesyonel standartlarıın geliştirilmesi, proje yönetimi araştırma-geliştirme programları gibi farklı faaliyetleri kapsayan yöntemler geliştirmiştir.

Proje yönetimiyle ilgili problemlerinin ve çözüm önerilerinin tartı̧ıımasını sağlamak, proje yönetiminin gelişimi ile ilgili araşıtırmalar yapma, proje yönetimi uygulamaları ile ilgili eğitici kılavuzları yayınlamak PMI'nın üstlenmiş olduğu bir görevdir. Bu anlamda PMI'nın yayınlamış olduğu ve dört yılda bir yayınlanan kılavuz PMBOK'tur.

PMI'nın yayınlamış olduğu PMBOK kılavuzunda proje yönetimi sürecini; başlangıç, planlama, uygulama, denetim ve kontrol, kapanış başlıkları altında beş sürece dayandırmaktadır. Yine PMBOK kılavuzunda tüm sektörleri kapsayan on bilgi alanı açıklanmıştır.

\subsubsection{Proje yönetim süreçleri}

Projenin gerçekleşmesindeki ilk süreç başlangıç sürecidir. Daha sonra gelen planlama süreci uygulama sürecine dönüşür. Uygulama süreci devam ederken izleme ve kontrol sürecine tabii tutulur. İzleme ve kontrol sürecinde elde edilen sonuçlarda planlama ve uygulama sürecindeki verilerde tutarlıık varsa proje yönetim süreci devam eder. Ancak tutarlılık sorunu varsa tekrar planlama sürecine geçilir ve gerekli düzeltmeler yapılır. Son aşamada proje yönetim sürecinde bir sıkıntı yoksa kapanış sürecine geçilerek proje sonlandırılır. Proje yönetim süreçleri aşamalarını sıralarsak;

- Başlangıç süreci

- Planlama süreci

- Yürütme süreci

- İzleme ve kontrol süreci

- Kapanış süreci

\subsubsection{Proje bilgi alanları}

Entegrasyon yönetimi: Anahtar bilgi alanı olarak kabul göre entegrasyon yönetimi diğer fonksiyonları da etkilemesi bakımından proje yönetiminin temelini oluşturur. 
Kapsam yönetimi: Proje için yapılacak olan işin planlanması, iş hacminin tanımlanması kapsam yönetimiyle sağlanır (Kocakulak, 1997, s.10).

Zaman yönetimi: Projenin başarılı bir şekilde sonuç alması için aktiviteler için gerekli sürenin belirlenmesi ve uygulanabilir iş takviminin oluşturulmasını içerir.

Aktivitelerin sürelerinin tahmini, sıralanmasını ve zamanın kontrolünü sağlar (Kocakulak,1997, s.13).

Maliyet yönetimi: Proje hedefine ulaşmasındaki belirlenen aktivitelerin hangi kaynak, ne kadar miktarda kullanılacağının belirlendiği ve hedeflenen bütçe ile projenin tamamlanmasını içerir.

Kalite yönetimi: Proje tamamlandığında öngörülen isteklerin kalite standartlarına uygun karşılanmasını sağlar. Kalite yönetimi kapsam, zaman ve maliyet kısıtları ile eşdeğer tutularak ve bu üç kısıtı da kapsayan bir çemberdir.

İnsan kaynakları yönetimi: Projenin gerçekleşmesinde rol alacak bireylerin seçimi, yönetilmesi ve organizasyonu ile ilgilenir. Bireyler arasındaki işbirliğinin, takım ruhunun en etkin şekilde oluşmasını sağlar.

İletişim yönetimi: Projenin gerçekleşmesi için gerekli bilginin oluşturulması, biriktirilmesi, paylaşımasını sağlar. İnsanlar arasında iletişim ağının kurulmasını ve yönetilmesini içerir.

Risk yönetimi: Projenin hedefine varmasındaki süreçte risk teşkil eden oluşumların tespit edilmesi ve önlenmesi için gerekli tedbirlerin alınmasını sağlar.

Tedarik yönetimi: Organizasyon içinde temin edilemeyen mal veya hizmet gibi intiyaçların temin edilmesini sağlar.

Paydaş yönetimi: Projenin sonuçlarından olumlu ya da olumsuz, doğrudan ya da dolaylı olarak etkilenecek şahıs, şirket ve kurumlara paydaşlar denir. Paydaşları belirleme, beklentilerini yönetme, paydaşlar arasındaki iletişimi sağlamak paydaş yönetiminin kapsamındadır.

\section{Proje Yönetim Teknikleri}

Proje yönetim teknikleri ile projenin işleyişini kontrol altına almak ve yönetmek mümkün olmuştur. Proje yönetim teknikleri projenin planlama evresinden itibaren yönetim sistemine dâhil olur, projenin sonlanmasına kadar sistem içerisinde yer alır. Planlama evresinde planlanan ve programlanan proje, uygulama evresinde proje yönetim tekniklerinin vasıtasıyla uygulamaya koyulur. Kontrol evresinde ise sapma olup olmadığı proje teknikleri ile kontrol edilir.

Proje yönetim teknikleri özellikle uygulama, izleme ve kontrol noktasında kapsamlı bir hizmet sunar. Planlama sürecinde belirlenmiş olan eylemlerin izleme ve kontrol sürecinde ne zaman başlayıp bitmesi gerektiğini gösterir. 
Türkiye'deki inşaat firmalarının proje planlama tekniklerini kullanmasındaki nedenleri sıralarsak; proje yönetiminin desteği, süreden kazanç sağlanarak gecikmelerin azaltıması, belirsizlik olan organizasyonda kontrolü sağlama ve uluslararası inşaat projelerinde artan rekabet gücünün yakalanmasıdır(Konakçı, 2006, s.63).

Proje planlama teknikleri projelerin öncelikle planlanması sonrasında uygulanmasında ve kontrolünde kullanılmaktadır. Planlama teknikleri proje yöneticilerine kolaylık sağlayarak oluşacak risklerin etkilerini tahmin ederek gerekli önlemlerin alınmasını sağlamaktadır. Proje planlama teknikleri kaynakların zaman ve maliyet unsurları açısından değerlendirilmesini sağlayarak proje kontrolüne yardımcı olur. Bu makale de genel olarak en çok kullanılan tekniklerden olan Gantt diyagramı tekniği, CPM ve PERT teknikleri incelenecektir.

\subsection{Gantt diyagramı tekniği}

1918 yılında Amerika'ı Henry Gantt tarafından geliştirilen en basit, en yaygın proje yönetim tekniğidir (Çoşkun, 2012, s.45). Gantt diyagramı basit bir teknik olduğu için daha çok küçük, karmaşık olmayan projelerde kullanılır.

Gantt diyagramı projenin her aşamasının sürelerinin başlangıç ve bitiş zamanlarının belirtilmesinden oluşur. Çabuk ve kolay hazırlanmasının yanında, zamanı yönetme ve sorunları anlamak için kullanılan bir tekniktir.

Gantt diyagramını grafik üzerinde düşeyde y ekseni, yatayda $x$ ekseni üzerinde gösterebiliriz. Grafik üzerinde x ekseni süreyi, y ekseni eylemleri simgeler. Belirlenmiş olan eylemler sırasıyla yukarıdan aşağıya, zamanlama ise soldan sağa doğru gösterilir.

\subsection{CPM ve PERT teknikleri}

Projenin planlama tekniği belirlenirken projenin yapısına, içeriğine ve hangi analizlere intiyaç duyduğuna göre belirlenebilir. Proje için önemli olan zaman ise, CPM veya PERT teknikleri seçilir. İlk defa uygulanacak bir konu üzerine proje yapılacak ise süre kesin olarak bilinmediği için PERT tekniği kullanılmalıdır. Proje daha önce uygulanmış ve süresinin bilindiği projelerde CPM tekniği kullanılmalıdır(Yalkı,2009, s.8).

CPM ve PERT teknikleri yakın tarihlerde ve birbirlerinden bağımsız olarak ortaya çıkmışlardır. Her iki teknik de temelde aynı çözüm önerileri sunmakta fakat faaliyet zamanları belirlenirken farlılıklar oluşturmaktadır. Bu tekniklerin temelde benzerlik göstermeleri CPM PERT teknikleri olarak birlikte ele alınmaktadır(Yalkı,2009, s.5).

PERT yöntemini Dr. C. E. Clarck adlı bir matematikçi geliştirmiştir. İlk kez 1958 yılında güdümlü füze atabilen nükleer başlıklı denizaltı yapımında kullanılmıştır (Akmut, Gür, 2006, s.10).CPM ise ilk kez kimyasal fabrikaların kurulmasında kullanılmıştır. Yöntemi ilk kez kullanan kimya alanında tanınan isim E, I.DuPont de Nemours firmasıdır (Çetmeli, Gür, 2006, s.10).

CPM projenin oluşması için yapılması gerekli olan tüm çalışmaları daha anlaşılabilir işlere dönüştürerek çözümleyen bir yöntemdir. Gerekli olan tüm işler bir organizasyon 
şeması olarak düzenlenir, her faaliyet için bir süre tahmini yapılır ve projenin her aşamasının tarihleri belirlenir(Gültekin,2007,s.79).

PERT-program değerleme ve gözden geçirme tekniği-,projenin oluşmasındaki gecikmeleri ve çalışmaları en aza indiren, faaliyetler arasında işbirliği sağlayan ve projelerin tanımlanmasını hızlandıran bir yöntem olarak tanımlanabilir(Gültekin,2007,s.80).

CPM çok kullanılan bir teknik olmasının yanında, bu yöntem projenin tam olarak planlandığı anlamına gelmemektedir. Bu yöntemde organizasyon şemasında yapılacak olan hata tüm projeyi etkiler. Projenin faaliyet ilişki ve sırasının bir programla sağlanması olanaksızdır.

\section{Proje Yönetiminin İnşaat Projelerinin Başarısına Etkileri}

Günümüzde artık teknolojinin ilerlemesi ve talep edilen ürünlerde fonksiyon ve çeşitliliğin artması proje üretim süreçlerinde proje yönetiminin mutlak bir gereklilik olduğunu ortaya koymuştur. Çünkü proje yönetimi daha kısa sonuç almayı, ürün elde etmede maliyetin azalmasını, yüksek kaliteyi ve tüm bunların yanında kar marjı sağlar.

Proje yönetiminin başarılı olmasının koşullarından biri, yönetiminin hangi projelerde ne şekilde, hangi teknik ve metodolojilerle uygulanacağını projenin büyüklüğüne ve riskine göre belirlemek önemlidir.

Projenin içeriklerine ve niteliklerine bakıldığında sonucu büyük ve kompleks projelerde belirlenen yol ile küçük projelerde belirlenen yolun farklı olacağını belirlemek gerekmektedir(Kır, 2007, s.21).

Genel yönetim kuralları, çalışmaları, kavramları, teknikleri, araçları proje yönetimi için temel oluşturur (Kır,2007, s.22). Proje yönetiminin başarılı olmasının koşullarından biri de bu temel bilgilerin bilgisini gerektirir.

Proje başarısının ölçütlerinden biri de hedef, bütçe ve zaman unsurlarının ne kadar verimli kullanıldığı ve istenilen hedefe ulaşılmasıyla ölçülür (Er,Kömürlü,2017, s.254).

Proje yönetimi başarılı bir sonuca ulaşmanın yoludur ve sorunları çözmek için belirlenmiş bir yöntemi vardır. Planlanmış bir yöntem uygulayarak sorunların başarıya ulaşması kaçınılmazdır. İncelenen proje yönetim metodolojileri ve proje yönetim teknikleri çerçevesinde başarılı bir proje ortaya koymak için şu adımlar atılmalıdır:

1. Sorunların tam olarak anlaşıldığından emin olunmalı.

2. Anlaşılan sorunu çözüme kavuşturmak için uygun bir eylem planı geliştirilmeli.

3. Bu eylemi gerçekleştirmek ve sorunu da çözüme kavuşturmak için sorumluluk birine verilmelidir.

4. Sorunun çözüme kavuşturulması için tarih belirlenmelidir(Newton,2006, s.107).

5. Yapılacak olan projenin iş hacminin, yapılması gerekli işlerin yani kapsamının anlaşılması gereklidir.

6. Aktiviteler için hedeflenen sürenin belirlenmesi ve uygulanması, zaman yönetiminin başarılı gerçekleşmesi projenin başarısını etkiler. 
7. İnşaat projesinde görev alacak kişiler arasındaki başarılı iletişim yönetimi iş aksaklıklarının engellenmesini sağlayarak projede başarıyı sağlar.

8. Proje yönetimi başlangıç sürecinde inşaat projesi için fizibilite çalışmaları yapılmalıdır. Bu çalışmalar projenin kaynak ve maliyet intiyacını ortaya koyarak ileride izlenecek olan proje stratejisi belirlenmesini sağlar.

9. İzleme ve kontrol sürecinin başarılı yönetilmesi projede yapılmış olan plana göre olabilecek sapmaları ortaya koyar, sapmalara göre gerekli planlama tekrar yapılarak projenin belirlenen hedeflere başarılı şekilde ulaşması sağlanır.

Başarılı bir proje yönetimi için maliyet, zaman, kapsam kısıtlarının belirlenen hedeflere ulaşılması proje finansörünün veya müşterinin memnuniyeti ile ölçülür(Esatoğlu,2010, s.7).Bu kısıtlardan herhangi birinde oluşacak olan değişiklik bir diğerini de etkilemektedir. Bu kısıtlar birbiri ile ilişkilidir. Bu kısıtlardan oluşacak olan sonuç kaliteyi ve dolayısı ile proje yönetiminin başarısını etkilemektedir.

\section{Sonuç}

Firmaların teknolojik yeniliklere açık, proje yönetim teknikleri ve proje metodolojileri hakkında donanımlı olmaları başarılı bir proje için olmazsa olmazdır.

İnşaatta proje yönetiminin başarılı bir proje oluşturması için proje yönetim tekniklerinin nasıl ve ne şekilde belirlenmesi gerektiği aktarılmıştır. Projelerin büyüklüğüne ve komplike olmalarına göre proje yönetim teknikleri seçilir. Proje yönetim teknikleri yapılacak olan işlerin sıralarını, başlangıç ve bitiş zamanlarını ortaya koyar, ortaya bir organizasyon şeması çıkarır. Bu şema projenin oluşmasındaki gecikmeleri ve dolayısı ile maliyeti en aza indirerek projenin başarılı bir şekilde sonlanmasını sağlar.

Proje metodolojilerinin projelerin kapsamlarına göre seçilmesi projenin başarıya ulaşmasındaki kıstaslardandır. Proje metodolojileri kavramı içerisinde aktarılan yönetim süreçleri ve bilgi alanları proje yönetimi uygulamasındaki önemli olan araçlardır. Süreçlerin eksiksiz olarak yönetilmesi gereklidir. PMI'nın yayınlamış olduğu PMBOK kılavuzunda yer alan bilgi alanları yönetimi birbirinden farklı disiplinlerden oluşmaktadır. $\mathrm{Bu}$ farklı disiplinlerin bir arada başarılı bir şekilde inşaat projesinde uygulanması ve başarılı bir şekilde sonlanması proje yönetimi sistemi sayesinde sağlanır.

İnşaat sektöründe uygulanan birçok projede, proje kapsamına giren unsurlar oldukça fazladır. Projelerin başlangıç, planlama, yürütme, kontrol ve kapanış evresine kadar ki tüm süreç boyunca kaynakların, kısıtların, maliyetin ve zamanın birlikte yönetilmesi zorunluluktur. Projenin her aşamasında projenin aksamadan başarılı bir şekilde sonuçlanması ancak yönetim teknikleri ile mümkündür (Kurşunoğlu, 2017, s.24). 


\section{Kaynaklar}

Ayaydın, Eyyüp, Bir Yatırım Projesi İçin Uygulanan ve Önerilen Proje Yönetim Sistemi, Yüksek Lisans Tezi, iTÜ, FBE, İstanbul, 2000, S.5.

Ata, Nuri, İlker, Türkiye'de Inşaat Sektöründe Profesyonel Proje Yönetim Standartlarının Kullanımı, Yüksek Lisans Tezi iTÜ, FBE, İstanbul, 2009, S.11,12,19, 27, 29.

Coşkun, Onur, Proje Teknikleri ve Uygulamalı Incelenmesi, Yüksek Lisans Tezi, İÜ, FBE, İstanbul, 2012, S.45.

Er Akın, Kömürlü Rüveyda, "Rafineri Projelerinde Planlamanın Önemi ve Başarılı Bir Planlama İçin Öneriler", Kocaeli Üniversitesi, Mimarlık ve Yaşam Dergisi, 2017, 2, S.253-264, ISSN: 2564-6109, DOI: 10.26835/my.349372

Esatoğlu, Nuray, Bilgi Teknolojileri Proje Yönetimi ve Başarı Koşulları, Lisans Tezi, AÜ, SBE, Ankara, 2010, S.7.

Günaydın H. Murat, Bolposta, Serdar, "Proje Yönetimi Uygulamalarının Yapımda Kullanımını Etkileyen Faktörler", Ege Mimarlık Dergisi, 2002

Gültekin, A. Tanju, Proje Yönetimi Yapım Öncesi Süreci, Palme Yayıncılık, Ankara,2007,S.79,80.

Gür, İlknur, Proje Yönetiminde PERT/CPM'in Proses Modeli ile Simüle Edilmesi ve Bir Uygulama, Yüksek Lisans Tezi, GTÜ, SBE, Gebze, 2006, S.10.

Kır, Ertürk, Yazılım Sektöründe Proje Yönetimi, Yüksek Lisans Tezi, KHÜ, SBE, stanbul,2007,S.41,42.

Kocakulak, Murat, Proje Yönetim Danışmanlığı Yapan Firma Bakışıyla Proje Yönetim Sistemi ve Uygulama Örneği, Yüksek Lisans Tezi, ITÜ, FBE, İstanbul,1997,S.4,9,10,13.

Konakçı, Cenk, Inşaat Planlama Teknikleri ve Yeni Yaklaşımlar-Türk Yüklenici Firmaları Alan Çalışması, Yüksek Lisans Tezi, ITÜ, FBE, İstanbul, 2006,S.63.

KPMG, Dünya ve Türkiye' de Eğilimler, KPMG İnşaat Sektörel Bakış Dergisi, 2018, S.4,https://assets.kpmg.com/content/dam/kpmg/tr/pdf/2018/01/sektorel-bakis-2018insaat.pdf, Erişim Tarihi: 20.11.2018, saat:17.10.

Kurşunoğlu, Zeki, Proje Yönetiminde Başarı Kriterleri Üzerine Bir Araştırma, Yüksek Lisans Tezi, GTÜ, SBE, 2017, S.24

Newton, Richard, Project Management Step by Step, Pearson, Optimist Yayıncılık, 2006,S.17,107.

Yalkı, İ., Proje Yönetimi ve CPM-PERT Teknikleri Üzerine Bir Uygulama, Yüksek Lisans Tezi, MÜ, SBE, İstanbul,2009,S.5,8. 